870-14, Rev. AE

$$
\begin{array}{r}
4758 \\
\text { P.4 } \\
N 92-13108
\end{array}
$$

\title{
INTERNATIONAL COMETARY EXPLORER (ICE)
}

\author{
TDS Mgr: N. Fanelli \\ NOPE: R. Nevarez \\ Project Mgr: P. Pashby (GSFC) \\ MOM: R. Wales (GSFC)
}

Launch Date: Aug. 12, 1978

Projected SC Life/DSN Support: 34 years/15 years

Project Responsibility: Goddard Space Flight Center (GSFC)

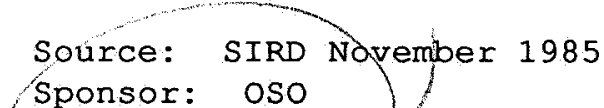

Sponsor: Oso

A. MISSION DESCRIPTION

The primary mission objectives of the International Cometary Explorer (ICE) comet mission are to determine the composition and physical state of the Giacobini-zinner comet's nucleus; to determine the processes that govern the composition and distribution of neutral and ionized species in the cometary atmosphere; and to investigate the interaction between the solar wind and the cometary atmosphere.

\section{B. FLIGHT PROFILE}

The spacecraft was in a halo orbit around the sun-Earth libration point until it was moved June 10, 1982 to the Earth's Geomagnetic Tail (GT). The spacecraft reached the GT in January 1983 and remained there until December 1983, at which time a lunar swing-by placed the spacecraft in a trajectory heliocentric orbit which encountered the comet Giacobini-zinner in September 
1985. The spacecraft provideed observations of the solar wind up-stream of comet Halley in 1986.

\section{COVERAGE}

\section{Coverage Goals}

Coverage by the 64-/70-m antennas has been provided from January 1984 to date and will continue through the end of mission, consisting of cruise and encounter support. (Prime support will be provided by the Madrid and Goldstone complexes, with additional support from the Canberra complex.)

The 64-m station at Usuda Japan, which is part of the Japanese Institute of Space and Astronautical Science (ISAS), provided supplemental support from May 1985 through Giacobini-zinner encounter (September 1985), and during the first Halley Radial (October 1985). Support consists of making telemetry recordings, which will be processed in nonreal-time at JPL. The number of hours of coverage (per day/week) will be determined by negotiation between NASA and ISAS.

Limited extended mission coverage will be provided from May 1986 through end of mission.

\section{Network Support}

The support provided by the DSN is indicated in the following table:

\begin{tabular}{|c|c|c|c|c|c|c|c|}
\hline \multirow[t]{2}{*}{ System } & & \multicolumn{2}{|c|}{ Goldstone } & Canberra & \multicolumn{2}{|c|}{ Madrid } & Usuda \\
\hline & & & $1415 \quad 16$ & $\begin{array}{llll}42 & 43 & 45 & 46\end{array}$ & 61 & 6366 & \\
\hline S-band & TLM & & $P$ & $P$ & & P & $S$ \\
\hline S-band & CMD & & $\mathrm{P}$ & & & $\mathrm{P}$ & \\
\hline s-band & TRK & B & $\mathrm{P}$ & B & $\mathrm{B}$ & $P$ & \\
\hline NOTE: & $\begin{array}{l}\mathrm{P}= \\
\mathrm{B}= \\
\mathrm{S}=\end{array}$ & $n t a$ & & & & & \\
\hline
\end{tabular}


D. FREQUENCY ASSIGNMENTS

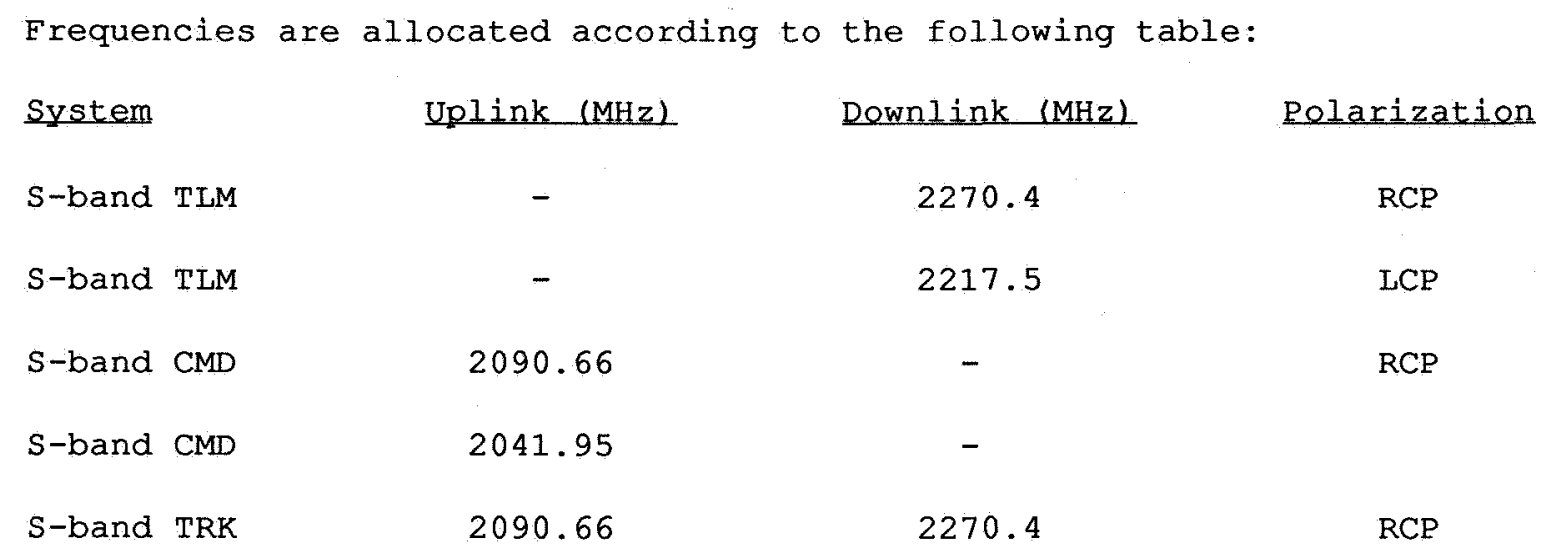

\section{E. SUPPORT PARAMETERS}

The support parameters for the Telemetry, Command, and Support Systems are listed below:

(1) Telemetry

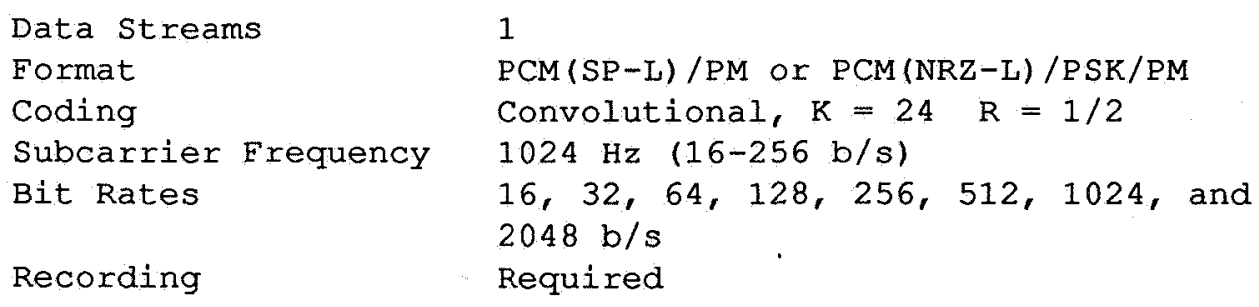

(2) Command

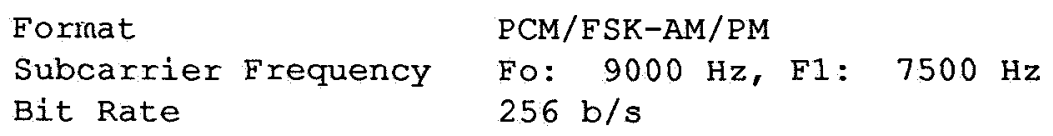

(3) Support

$\begin{array}{ll}\text { Uplink Power } & 10 \text { to } 80 \mathrm{~kW} \\ \text { Antenna Rate } & \text { Sidereal } \\ \text { Antenna Angle Data } & \text { Not required } \\ \text { Antenna Autotrack } & \text { Not required } \\ \text { Doppler Rate } & \text { Sidereal } \\ \text { Range Format } & \text { DSN Standard } \\ \text { Recording } & \\ \quad \text { - Analog } & \text { Not required } \\ \text { Digital } & \text { Required }\end{array}$


870-14, Rev. AE

F. TRACKING SUPPORT RESPONSIBILITY

The allocation of responsibilities for tracking support is listed in the following table:

$\begin{array}{ll}\text { Mission Phase } & \text { Support Responsibility } \\ \text { Earth Orbit } & \text { STDN (through Dec. 1983) } \\ \text { Planetary } & \text { DSN (after Dec. 1983) }\end{array}$

Planetary

DSN (after Dec. 1983) 